\title{
Endoscopic endonasal surgery for epidermoid and dermoid cysts: a 10-year experience
}

\author{
Francisco Vaz-Guimaraes, MD, ${ }^{1,2}$ Maria Koutourousiou, MD, ${ }^{1}$ John R. de Almeida, MD,, ${ }^{3,4}$ \\ Elizabeth C. Tyler-Kabara, MD, PhD, ${ }^{1}$ Juan C. Fernandez-Miranda, MD, ${ }^{1}$ Eric W. Wang, MD, ${ }^{3}$ \\ Carl H. Snyderman, MD, MBA, ${ }^{3}$ and Paul A. Gardner, MD'
}

\begin{abstract}
${ }^{2}$ Department of Neurosurgery, Michael E. DeBakey VA Medical Center/Baylor College of Medicine, Houston, Texas; ${ }^{4}$ Department of Otolaryngology-Head and Neck Surgery, University of Toronto, Ontario, Canada; and Departments of ${ }^{3}$ Otolaryngology and ${ }^{1}$ Neurological Surgery, University of Pittsburgh School of Medicine, Pittsburgh, Pennsylvania
\end{abstract}

OBJECTIVE Epidermoid and dermoid cysts may be found along the cranial base and are commonly resected via open transcranial approaches. The use of endoscopic endonasal approaches for resection of these tumors has been rarely reported.

METHODS The authors retrospectively reviewed the medical records of 21 patients who underwent endoscopic endonasal surgery for epidermoid and dermoid cyst resection at the University of Pittsburgh Medical Center between January 2005 and June 2014. Surgical outcomes and variables that might affect the extent of resection and complications were analyzed.

RESULTS Total resection (total removal of cyst contents and capsule) was achieved in 8 patients (38.1\%), near-total resection (total removal of cyst contents, incomplete removal of cyst capsule) in 9 patients $(42.9 \%)$, and subtotal resection (incomplete removal of cyst contents and capsule) in 4 patients (19\%). Larger cyst volume $\left(\geq 3 \mathrm{~cm}^{3}\right)$ and intradural location (15 cysts) were significantly associated with nontotal resection ( $p=0.008$ and 0.0005 , respectively). In the whole series, surgical complications were seen in 6 patients $(28.6 \%)$. No complications were observed in patients with extradural cysts. Among the 15 patients with intradural cysts, the most common surgical complication was postoperative CSF leak (5 patients, 33.3\%), followed by postoperative intracranial infection (4 patients, $26.7 \%$ ). Larger cysts and postoperative CSF leak were associated with intracranial infection ( $p=0.012$ and 0.028 , respectively). Subtotal resection was marginally associated with intracranial infection when compared with total resection $(p=0.091)$. All patients with neurological symptoms improved postoperatively with the exception of 1 patient with unchanged abducens nerve palsy.

CONCLUSIONS Endoscopic endonasal approaches may be effectively used for resection of epidermoid and dermoid cysts in carefully selected cases. These approaches are recommended for cases in which a total or near-total resection is possible in addition to a multilayer cranial base reconstruction with vascularized tissue to minimize the risk of intracranial infection.

https://thejns.org/doi/abs/10.3171/2017.7.JNS162783

KEY WORDS epidermoid cysts; dermoid cysts; endoscopic endonasal approaches; outcome; postoperative intracranial infection; skull base

$\mathrm{E}$ PIDERMOID and dermoid cysts are congenital nonneoplastic lesions representing approximately $1 \%$ of all intracranial tumors. They arise from an abnormality during gastrulation that leads to an ectopic inclusion of ectodermal cells in the neural tube. These lesions are characterized by a slow growth rate, are commonly found along the cranial base, and may spread across the subarachnoid cisterns, often reaching large dimensions before causing neurological symptoms. Epidermoid cysts have smooth capsules and are usually located off midline (e.g., cerebellopontine angle [CPA] cistern). In contrast, dermoid cysts have thicker capsules and a predilection for midline structures..$^{24,29,44}$

Resection is the only effective treatment for these le-

ABBREVIATIONS CN = cranial nerve; $\mathrm{CPA}=$ cerebellopontine angle; EEA = endoscopic endonasal approach; EES = endoscopic endonasal surgery; ICA = internal carotid artery.

SUBMITTED November 4, 2016. ACCEPTED July 24, 2017.

INCLUDE WHEN CITING Published online March 16, 2018; DOI: 10.3171/2017.7.JNS162783. 
sions. Historically, epidermoid and dermoid cysts have been resected via open transcranial approaches. ${ }^{8,24,34,44}$ Supratentorial cysts are often resected via frontotemporal craniotomies and infratentorial cysts via suboccipital or retrosigmoid craniotomies. For lesions situated at the ventral aspect of the cranial base, the endoscopic endonasal approaches (EEAs) may provide a more direct surgical corridor with less manipulation of neurovascular structures compared with open transcranial approaches..$^{15,16}$ Nonetheless, the endoscopic endonasal resection of ventrally located epidermoid and dermoid cysts has been rarely reported. $7,9,25,26,31,38,42,45$

We present a 10-year experience in the management of 21 patients with epidermoid and dermoid cysts treated with endoscopic endonasal surgery (EES) in a single institution. The benefits of this surgical approach and factors that might be associated with incomplete cyst resection and postoperative complications were analyzed.

\section{Methods}

\section{Patient Population}

With approval of the University of Pittsburgh institutional review board, we retrospectively reviewed the medical records of patients with epidermoid and dermoid cysts treated with EES at the Center for Cranial Base Surgery of the University of Pittsburgh Medical Center between January 2005 and June 2014. Patients with purely extracranial disease (e.g., nasal dermoids with no intracranial extension) were excluded. A total of 21 patients, 13 male and 8 female, with a mean age of 29.6 years (range 2-65 years), were identified. Fifteen patients presented with primary lesions, whereas 6 had been previously treated elsewhere. Twelve of the cysts were epidermoid and 9 were dermoid. Of note, 6 patients included in this cohort had been previously reported in another paper. ${ }^{6}$

\section{Clinical Presentation and Imaging Findings}

The clinical presentation was variable and related to cyst location. The dominant clinical symptom was visual impairment affecting visual acuity, visual fields, or both, and occurring in 9 patients $(42.9 \%)$. Six patients presented with persistent headache $(28.6 \%)$, 3 with trigeminal neuralgia (14.3\%), and 2 with pituitary insufficiency (9.5\%). Quadriparesis and abducens nerve palsy were seen in 1 patient (4.8\%). One patient had a cyst diagnosed incidentally. Four pediatric patients presented with nasal symptoms (nasal obstruction or deformity).

Preoperative MRI studies were available for every case and showed variable cyst location and volume. Fifteen cysts were located intradurally: 10 cysts (7 epidermoid and 3 dermoid) were located in the suprasellar cistern, 3 epidermoid cysts were located in the prepontine cistern, 1 epidermoid was located in the parasellar/cavernous sinus region, and 1 dermoid was located in Meckel's cave. Six cysts were located extradurally but involved the intracranial space: 5 nasal dermoids with invasion of the anterior cranial fossa and 1 epidermoid in the infratemporal fossa extending into the middle cranial fossa. Cyst volume was estimated by a modified ellipsoid formula $([\mathrm{A} \times \mathrm{B} \times \mathrm{C}] / 2)$, where $\mathrm{A}, \mathrm{B}$, and $\mathrm{C}$ represent the maximum diameters of the cyst in each of 3 dimensions. The median cyst volume was $3.8 \mathrm{~cm}^{3}$ (range $0.2-81.4 \mathrm{~cm}^{3}$ ). For lesions located in the subarachnoid space, the presence of cyst capsule enhancement on T1-weighted postcontrast MR images was also analyzed. Table 1 summarizes patient data.

\section{Surgical Management}

All patients underwent EES. The goal of surgery was decompression of the brainstem and/or compressed neurovascular structures and maximum safe cyst resection. The approach was customized for location and cyst extension. The cysts located in the suprasellar cistern were resected by a transplanum approach; nasal dermoids with anterior cranial fossa extension were resected by a transfrontal/ cribriform approach; cysts in the prepontine cistern were resected by a transclival approach; the cyst in the parasellar region extending into the cavernous sinus was resected by a transellar-transcavernous approach; and 1 Meckel's cave dermoid and 1 epidermoid in the infratemporal fossa extending into the middle cranial fossa were resected via a transpterygoid approach. In cases of intraoperative CSF leak, the pedicled nasoseptal flap was used for cranial base reconstruction in all but the first 2 cases.

\section{Evaluation of Surgical Results}

Clinical outcome following EES was assessed with postoperative visual tests, clinical examination, and endocrine studies as indicated. The extent of cyst resection was based on operative reports (surgeon's intraoperative impression) and confirmed by the first postoperative MRI. Total resection was defined as the complete removal of both cyst contents and capsule; near-total resection was defined as complete content removal and incomplete capsule removal; and subtotal resection was defined as incomplete resection of both cyst contents and capsule. Postoperative diffusion-weighted MRI sequences were employed in all epidermoid cases to confirm degree of resection.

\section{Statistical Analysis}

Data are presented as numbers of cases (\%) for categorical variables and mean, $\mathrm{SD}$, and median for continuous variables. Potential risk factors for incomplete cyst resection and postoperative intracranial infection (i.e., bacterial meningitis and intracranial abscess) were assessed by Fisher's exact test. The impact of cyst volume on extent of resection and risk of postoperative intracranial infection was assessed by the Wilcoxon rank-sum test on logtransformed volume. Data were collected using Microsoft Excel 2010 (Microsoft Corp.). Analyses were performed with SAS v9.3 (SAS Institute). All tests were 2-sided at alpha $=0.05$.

\section{Results \\ Clinical Outcome}

Most patients showed improvement of their presenting symptoms. Improvement or normalization of vision was achieved in all 9 patients who initially presented with visual impairment. Preexisting headaches also improved or resolved in every case. Among the 3 patients who present- 
TABLE 1. Summary of demographic and clinical characteristics of patients with epidermoid and dermoid cysts

\begin{tabular}{ccllcll}
\hline Case No. & Pt Age (yrs), Sex & \multicolumn{1}{c}{ Clinical Sx } & Cyst Location & Vol $\left(\mathrm{cm}^{3}\right)$ & MR Enhancement & Presentation Histology \\
\hline 1 & $54, \mathrm{M}$ & HA & NC/ACF & 5.6 & NA $^{*}$ & Recurrent dermoid \\
\hline 2 & $18, \mathrm{~F}$ & HA & Suprasellar & 3.8 & No & Primary epidermoid \\
& & Vision loss & & & \\
\hline 3 & $49, \mathrm{M}$ & Vision loss & Suprasellar & 17.2 & No & Recurrent epidermoid \\
\hline 4 & $4, \mathrm{~F}$ & Nasal mass & NC/ACF & 2.7 & NA & Recurrent dermoid \\
\hline 5 & $11, \mathrm{M}$ & Vision loss & Suprasellar & 81.4 & Yes & Primary dermoid \\
\hline 6 & $28, \mathrm{M}$ & Vision loss & Suprasellar & 13.3 & No & Primary epidermoid \\
\hline 7 & $29, \mathrm{~F}$ & TN & IFT/MCF & 2.9 & NA & Primary epidermoid \\
\hline 8 & $60, \mathrm{~F}$ & Vision loss & Suprasellar & 0.6 & No & Recurrent epidermoid \\
\hline 9 & $27, \mathrm{M}$ & Vision loss & Suprasellar & 7.9 & No & Primary dermoid \\
\hline 10 & $2, \mathrm{~F}$ & Nasal mass & NC/ACF & 0.2 & NA & Primary dermoid \\
\hline 11 & $16, \mathrm{M}$ & Nasal mass & NC/ACF & 1.8 & NA & Primary dermoid \\
\hline 12 & $14, \mathrm{M}$ & Incidental finding & Prepontine & 2.9 & No & Primary epidermoid \\
\hline 13 & $2, \mathrm{M}$ & Nasal mass & NC/ACF & 0.5 & NA* & Primary dermoid \\
\hline 14 & $16, \mathrm{M}$ & HA & Suprasellar & 4.0 & Yes & Primary epidermoid \\
\hline 15 & $33, \mathrm{M}$ & HA & Prepontine & 45.5 & Yes & Primary epidermoid \\
\hline 16 & $19, \mathrm{~F}$ & TN & Meckel's cave & 7.2 & Yes & Primary dermoid \\
\hline 17 & $48, \mathrm{M}$ & Quadriparesis & Prepontine & 19.9 & Yes & Primary epidermoid \\
\hline 18 & $25, \mathrm{~F}$ & Vision loss & Suprasellar & 2.0 & Yes & Recurrent dermoid \\
\hline 19 & $66, \mathrm{~F}$ & HA/TN, CN VI palsy & Parasellar & 1.9 & Yes & Primary epidermoid \\
\hline 20 & $45, \mathrm{M}$ & HA/hypopit, vision loss & Suprasellar & 1.9 & Yes & Primary epidermoid \\
\hline 21 & $48, \mathrm{M}$ & Hypopit, vision loss & Suprasellar & 10.1 & Yes & Recurrent epidermoid \\
\hline
\end{tabular}

$\mathrm{HA}=$ headaches; hypopit = hypopituitarism; IFT/MCF = infratemporal/middle cranial fossa; $\mathrm{NA}=$ not applicable; $\mathrm{NC} / \mathrm{ACF}=$ nasal cavity/anterior cranial fossa; $\mathrm{pt}=$ patient; $\mathrm{Sx}=$ symptoms; $\mathrm{TN}=$ trigeminal neuralgia.

${ }^{*}$ Extradural.

ed with trigeminal neuralgia, pain subsided in every case, although the patient with a dermoid cyst located within Meckel's cave developed persistent hemifacial hypesthesia. Two patients with preexisting hypopituitarism and 1 patient with cranial nerve $(\mathrm{CN})$ VI palsy experienced no change in these conditions after surgery. One patient who presented with quadriparesis due to brainstem compression completely recovered following cyst resection. Among the 4 pediatric patients with nasal dermoid cysts invading the anterior cranial fossa, nasal deformity and/or obstruction resolved after surgery.

\section{Extent of Resection}

The resection achieved was total in 8 patients (38.1\%), near total (residual capsule) in 9 patients (42.9\%), and subtotal (residual cyst contents) in 4 patients (19\%). Total resection was achieved in all 6 patients with extradural disease. Of the remaining 15 patients with purely intradural disease, the resection achieved was total in $2(13.3 \%)$, near total in $9(60 \%)$, and subtotal in $4(26.7 \%)$.

To better understand the role of EES in epidermoid and dermoid cyst resection, we analyzed the rates of total cyst resection according to recurrent disease status, cyst location (intradural vs extradural), presence of contrast enhancement on preoperative MRI, and cyst volume (Table 2$)$. Higher cyst volume $\left(\geq 3 \mathrm{~cm}^{3}\right)$ was significantly associated with nontotal resection $(\mathrm{p}=0.008)$. Subtotal resection (larger cyst residuals) was most commonly ob- served in larger suprasellar and prepontine cysts, in which cyst residuals were often located in the third ventricle and CPA cistern. Cysts with involvement of the subarachnoid space (intradural location) were significantly associated with nontotal resection $(\mathrm{p}=0.0005)$, although these cysts were also larger than the extradural ones $(p=0.04)$. Recurrent disease and presence of contrast enhancement on preoperative MRI were not limitations of total cyst resection in EES.

\section{Complications and Management}

In the whole series, surgical complications were seen in 6 patients $(28.6 \%)$. There were no surgical complications among the 6 patients with extradural cysts. However, of the remaining 15 patients with intradural cysts, 6 patients (40\%) had postoperative complications, including postoperative CSF leak in 5 (33.3\%) and postoperative intracranial infection (i.e., bacterial meningitis or intracranial abscess) in 4 (26.7\%). Two CSF leaks occurred in the first 2 intradural cases (cases 2 and 3) when the pedicled nasoseptal flap had not been routinely used for cranial base reconstruction at our institution. In the remaining 13 patients with intradural cysts, when the flap was available for reconstruction, postoperative CSF leak occurred in only 3 patients (cases 6,15 , and 21) $(\mathrm{p}=0.095)$. Among these last 3 patients, one (case 15) presented with aseptic meningitis that was successfully managed with steroids, but resulted in perioperative hydrocephalus, which almost certainly contributed to 
TABLE 2. Cyst resection rates according to multiple variables

\begin{tabular}{lccc}
\hline \multicolumn{1}{c}{ Variable } & $\begin{array}{c}\text { Nontotal } \\
\text { Resection }\end{array}$ & $\begin{array}{c}\text { Total } \\
\text { Resection }\end{array}$ & p Value \\
\hline Disease at presentation & & & 0.631 \\
\hline Primary $(n=15)$ & $10(66.7)$ & $5(33.3)$ & \\
\hline Recurrent $(n=6)$ & $3(50)$ & $3(50)$ & \\
\hline Location & & & 0.0005 \\
\hline Intradural $(n=15)$ & $13(86.7)$ & $2(14.3)$ & \\
\hline Extradural $(n=6)$ & $0(0)$ & $6(100)$ & \\
\hline MRI contrast enhancement & & & $>0.99$ \\
\hline No enhancement $(n=6)$ & $5(83.3)$ & $1(16.7)$ & \\
\hline Enhancement $(n=9)$ & $8(88.9)$ & $1(11.1)$ & \\
\hline Preop vol & & & \\
\hline Mean & $16.7 \mathrm{~cm}^{3}$ & $2.0 \mathrm{~cm}^{3}$ & \\
\hline SD & $22.7 \mathrm{~cm}^{3}$ & $1.8 \mathrm{~cm}^{3}$ & \\
\hline Median & $7.9 \mathrm{~cm}^{3}$ & $1.9 \mathrm{~cm}^{3}$ & \\
\hline$<3 \mathrm{~cm}^{3}$ & $30.0 \%$ & $70.0 \%$ & \\
\hline$\geq 3 \mathrm{~cm}^{3}$ & $90.9 \%$ & $9.1 \%$ & 0.008 \\
\hline
\end{tabular}

Data are numbers of case (\%) unless otherwise indicated. Boldface type indicates statistical significance.

* Intradural cysts only.

the occurrence of the fistula. All CSF leaks were treated with additional endonasal repair and lumbar drainage.

There were 4 cases of postoperative intracranial infection (cases 3, 5, 6, and 21). In 2 cases (cases 3 and 6) the infection evolved from bacterial meningitis to eventual intracranial abscess, and in one of these 2 cases (case 6), the patient went on to develop vasospasm, stroke, and seizures. One patient (case 21) suffered perioperative bacterial meningitis without any other complications (including abscess), and one other patient (case 5) presented with a delayed intracranial abscess 6 months following the operation with no warning signs of infection or CSF leakage. Cases of bacterial meningitis were treated with broadspectrum antibiotics. All intracranial abscesses were treated with surgical drainage (stereotactic aspiration in 2 cases and endoscopic endonasal drainage in 1 case) and broad-spectrum antibiotics. Four patients (cases 3, 6, 15, and 21), all of whom had either aseptic or septic meningitis, developed hydrocephalus and were treated with ventriculoperitoneal shunt placement.

Two patients with prepontine epidermoid cysts (cases 15 and 17) developed transient CN VI palsies immediately after surgery, which completely resolved after several days. One patient with a recurrent suprasellar epidermoid cyst (case 8) developed new hypopituitarism and diabetes insipidus requiring hormonal replacement. No new endocrinopathies were observed in the remaining 9 patients with suprasellar cysts.

To better understand the risk factors that might be associated with the occurrence of postoperative intracranial infection (bacterial meningitis and intracranial abscess), our results were analyzed according to recurrent disease status, extent of resection, cyst location, occurrence of postoperative CSF leak, and cyst volume. As shown in Table 3, larger cysts and postoperative CSF leak were
TABLE 3. Risk factors for postoperative intracranial infection

\begin{tabular}{|c|c|c|c|}
\hline \multirow[b]{2}{*}{ Variable } & \multicolumn{2}{|c|}{ Postop Infection } & \multirow{2}{*}{$\begin{array}{c}p \\
\text { Value }\end{array}$} \\
\hline & No & Yes & \\
\hline \multicolumn{2}{|l|}{ Disease at presentation } & & 0.544 \\
\hline Primary $(n=15)$ & $13(86.7)$ & $2(13.3)$ & \\
\hline Recurrent $(n=6)$ & $4(66.7)$ & $2(33.3)$ & \\
\hline \multicolumn{2}{|l|}{ Extent of resection I* } & & 0.108 \\
\hline Total $(n=8)$ & $8(100)$ & $0(0)$ & \\
\hline Near total $(n=9)$ & $7(78)$ & $2(22)$ & \\
\hline Subtotal $(n=4)$ & $2(50)$ & $2(50)$ & \\
\hline \multicolumn{2}{|l|}{ Extent of resection $\mathrm{II}^{*}$} & & 0.1312 \\
\hline Total $(n=8)$ & $8(100)$ & $0(0)$ & \\
\hline Nontotal $(n=13)$ & $9(69)$ & $4(31)$ & \\
\hline \multicolumn{2}{|l|}{ Extent of resection III* } & & 0.091 \\
\hline Total $(n=8)$ & $8(100)$ & $0(0)$ & \\
\hline Subtotal $(n=4)$ & $2(50)$ & $2(50)$ & \\
\hline \multicolumn{2}{|l|}{ Cyst location } & & 0.28 \\
\hline Intradural $(n=15)$ & $11(73.3)$ & $4(26.7)$ & \\
\hline Extradural $(n=6)$ & $6(100)$ & $0(0)$ & \\
\hline \multicolumn{2}{|l|}{ Postop CSF leak } & & 0.028 \\
\hline No $(n=16)$ & $15(93.8)$ & $1(6.2)$ & \\
\hline Yes $(n=5)$ & $2(40)$ & $3(60)$ & \\
\hline \multicolumn{2}{|l|}{ Preop vol } & & 0.012 \\
\hline Mean & $6.6 \mathrm{~cm}^{3}$ & $30.5 \mathrm{~cm}^{3}$ & \\
\hline SD & $11.0 \mathrm{~cm}^{3}$ & $34.1 \mathrm{~cm}^{3}$ & \\
\hline Median & $2.9 \mathrm{~cm}^{3}$ & $15.2 \mathrm{~cm}^{3}$ & \\
\hline$<3$ & $10(100)$ & $0(0)$ & \\
\hline$\geq 3$ & $7(63.6)$ & $4(36.4)$ & 0.090 \\
\hline \multicolumn{4}{|c|}{$\begin{array}{l}\text { Data are numbers of case (\%) unless otherwise indicated. Boldface type } \\
\text { indicates statistical significance. } \\
\text { * Extent of resection was analyzed in } 3 \text { different comparisons: I, total versus } \\
\text { near total versus subtotal, separately; II, total versus nontotal, which includes } \\
\text { all near-total and subtotal cases combined; and III, total versus subtotal cases. } \\
\text { A trend toward increased risk of infection was only seen in the third compari- } \\
\text { son, reinforcing the hypothesis that the larger the residual, the higher the risk } \\
\text { of infection. }\end{array}$} \\
\hline
\end{tabular}

significantly associated with intracranial infection $(\mathrm{p}=$ 0.012 and 0.028 , respectively). Of note, cyst size greater than $9 \mathrm{~cm}^{3}$ was also marginally associated with increased CSF leak rate $(p=0.089)$. In terms of extent of resection, there was a trend toward increased risk of infection following subtotal resection compared with total resection ( $p$ $=0.091)$. Recurrent disease and intradural location were not associated with increased risk of postoperative infection ( $\mathrm{p}=0.544$ and 0.255 , respectively). Given the small sample size, a multivariate analysis was not possible.

\section{Recurrence}

During follow-up ranging from 2 to 79 months, with an average of 27.4 months, local recurrence was observed in 2 patients who had incomplete resection of suprasellar dermoid cysts. One of these patients presented with an asymptomatic regrowth and has been closely followed, whereas the other, due to the development of neurological 

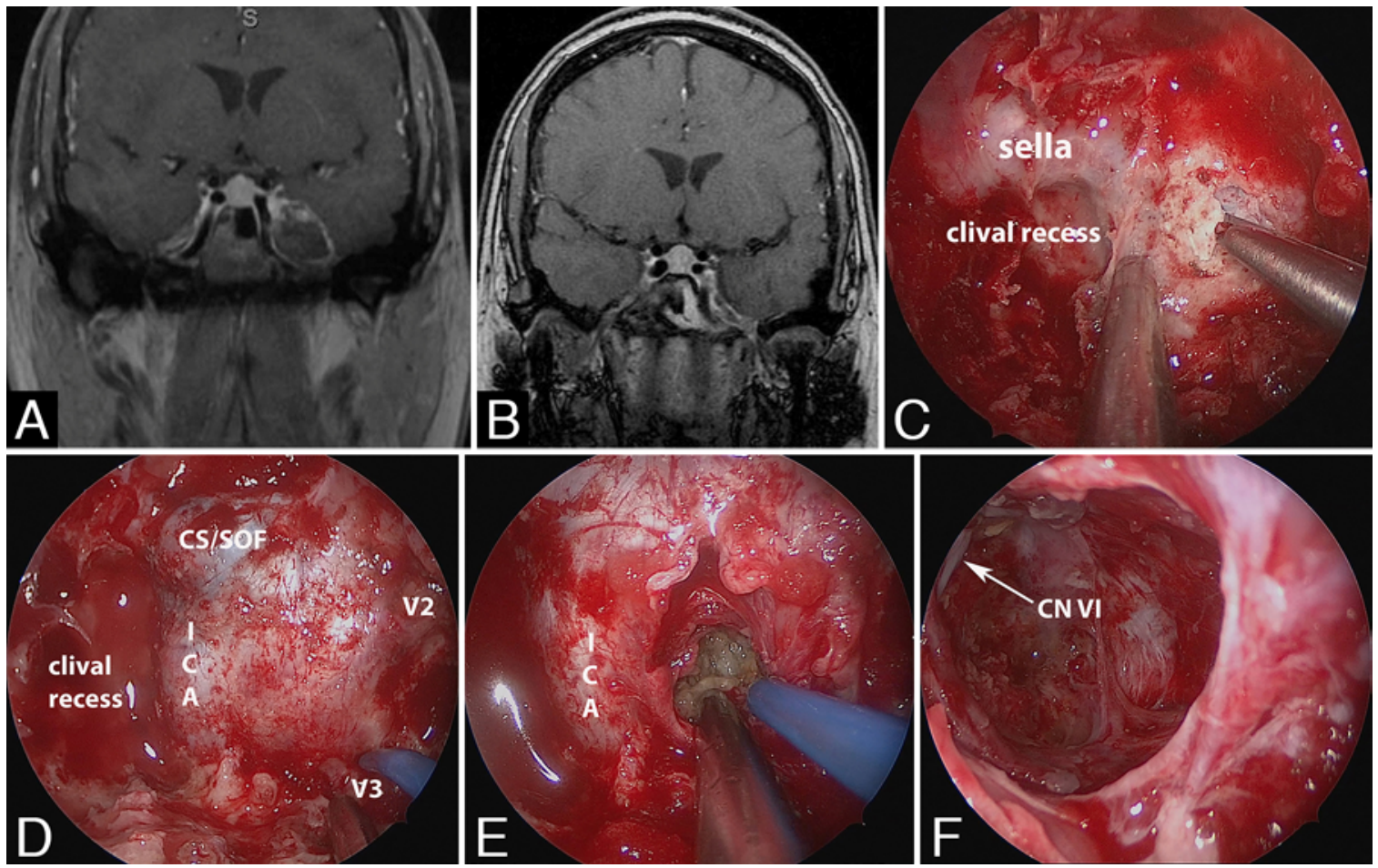

FIG. 1. Case 16. Endoscopic endonasal transpterygoid approach for Meckel's cave dermoid cyst in a 19-year-old woman. A and B: Preoperative (A) and postoperative (B) T1-weighted postcontrast coronal MR images. The preoperative image shows a cystic lesion within Meckel's cave. C and D: Intraoperative images obtained through a $0^{\circ}$ endoscope showing removal of bone over the left Meckel's cave (C) and exposed dura of the left Meckel's cave with nerve stimulator on V3 (D). E: Dissection of tumor from Meckel's cave with monitoring of cranial nerve function. F: View of residual cyst attached to the superomedial compartment of Meckel's cave next to the abducens nerve (CN VI). CS/SOF = cavernous sinus/superior orbital fissure. Figure is available in color online only.

symptoms, underwent a frontotemporal craniotomy for cyst resection 62 months after the endonasal approach. A transcranial approach was chosen due to lateral extension of the cyst toward the sylvian fissure. Another asymptomatic growth has been closely followed in a patient who had complete resection of a parasellar epidermoid cyst.

A life table with censored data analysis accounting for length of follow-up revealed, for the entire cohort, a cumulative recurrence-free survival of $91 \%$ and $60.7 \%$ at 3 and 5 years, respectively. The recurrence-free survival rate for patients who underwent complete cyst resection was $87.5 \%$ at 3 and 5 years; in the subset of patients whose cysts were incompletely resected, these rates were $100 \%$ and $33.4 \%$, respectively. Given the small sample size, no statistical significance was identified. On last consultation, 18 patients were asymptomatic; 1 patient was left with a moderate disability as a result of tumor bed infection, stroke, and the development of recurrent seizures. One patient died of unrelated causes.

\section{Illustrative Cases \\ Case 16}

This 19-year-old woman presented with medically refractory, left-sided trigeminal neuralgia. MRI revealed a cystic lesion within Meckel's cave (Fig. 1A).

An endoscopic endonasal left transpterygoid approach was performed using the 2-surgeon, 4-hands technique (Fig. 1B). Upon completion of the approach, the dura of the anterior wall of Meckel's cave was opened, and the cyst contents were removed (Fig. 1C-E). Small fragments of the cyst capsule attached to the abducens nerve along the superomedial aspect of the tumor cavity were left to preserve neurological function (Fig. 1F). A small CSF leak from the porus trigeminis was identified, and therefore reconstruction was performed with a contralateral vascularized nasoseptal flap. The patient developed persistent hemifacial hypesthesia along the distribution of the maxillary and mandibular divisions of the trigeminal nerve (V2 and V3), but her postoperative course was otherwise uneventful and her trigeminal neuralgia resolved.

\section{Case 17}

This 48-year-old man presented with progressive quadriparesis and ataxia. MRI showed a very large prepontine epidermoid cyst causing significant brainstem compression and displacement (Fig. 2A).

An endoscopic endonasal transclival approach with an interdural pituitary transposition was performed using the 2-surgeon, 4-hands technique (Fig. 2B).$^{10}$ After the cyst was debulked, the capsule was gently and bimanually dissected from the surrounding structures using a microsurgical technique (Fig. 2C). Small fragments were left attached to the pial surface of the pons and to the left abducens nerve to preserve function (Fig. 2D). Copious saline irrigation flushed any debris from the subarachnoid space. A vascularized nasoseptal flap was used for 

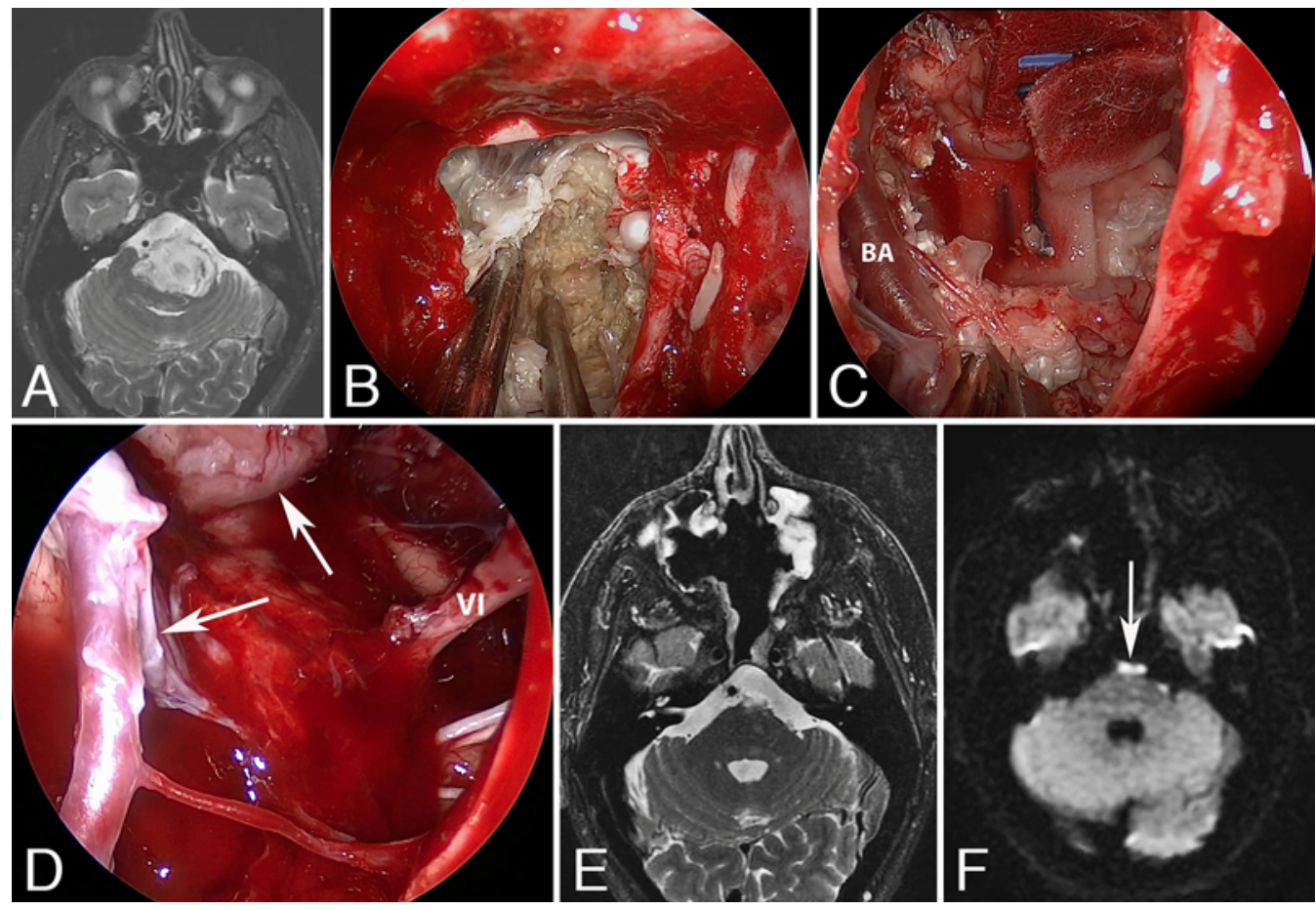

FIG. 2. Case 17. Endoscopic endonasal transclival approach for prepontine epidermoid cyst. A: Preoperative T2-weighted axial MR image showing a large prepontine epidermoid cyst. B-D: Intraoperative images. Two-suction dissection of prepontine epidermoid cyst was performed using an endoscopic endonasal transclival approach (B). The tumor was sharply dissected from the basilar artery (BA) and its branches using scissors (C). Small fragments of residual cyst tissue were left attached to the pial surface of the brainstem (D, arrows). E and F: Postoperative T2-weighted axial MR image (E) and diffusion-weighted imaging sequence (F) demonstrating brainstem decompression and cyst residual (arrow). VI = CN VI. Figure is available in color online only.

the final layer of a multilayer cranial base reconstruction. The postoperative course was complicated by a transient left CN VI palsy. The patient recovered completely from his preoperative neurological symptoms, and he remains asymptomatic and neurologically normal 6 months later.

\section{Discussion}

\section{Goals of Surgery}

The surgical treatment of epidermoid and dermoid cysts may be challenging. These lesions grow as a result of epithelial desquamation. Glandular secretion also plays a key role in the enlargement of dermoid cysts. The breakdown products produced during the desquamation of epithelial cells may induce a chronic inflammatory reaction that increases the tendency of the cyst to adhere to surrounding structures, which often precludes total removal and increases the likelihood of perioperative neurovascular injuries and cyst recurrence..$^{8,29}$ The extent of resection must be decided intraoperatively based on the adherence of the cyst wall to surrounding neurovascular structures and the risk of iatrogenic injury. ${ }^{11,35}$

Total resection is often considered the preferred treatment because it offers a cure..$^{11,43,44}$ Talacchi et al.$^{40}$ have reported a higher rate of cyst-free survival with total resection. On the other hand, Schiefer and Link ${ }^{36}$ have demonstrated similar rates of recurrence for total and subtotal cyst resection, and others have advocated conservative resection, arguing that the linear growth pattern of these cysts decreases the chance of a symptomatic recurrence in a short period of time. ${ }^{4,11,27}$ Thus, patient age, preoperative neurological status, and operative findings of firm cyst adhesions must guide the surgical strategy. Given the benign nature of these cysts, we think that the addition of new neurological deficits is hardly justified. Continuous intraoperative neurophysiological monitoring also plays an important role in the prevention of neural injury. ${ }^{37}$

\section{Endoscopic Endonasal Surgery}

Endoscopic endonasal surgery (EES) has been commonly used for the treatment of a myriad of cranial base lesions in recent decades. Despite its feasibility, safety, and efficacy for other lesions, endoscopic endonasal resection of epidermoid and dermoid cysts has been rarely reported (Table 4).

The use of endoscopic endonasal approaches (EEAs) for resection of ventrally situated cysts (cysts in the frontonasal junction or suprasellar, interpeduncular, prepontine, or premedullary cisterns) has several advantages compared with open transcranial approaches. The lack of brain, neural, or vascular retraction; excellent cosmetic results due to the avoidance of skin incisions; and the potential for shorter surgical time and length of hospitalization are among the most notable ones. Chiefly, EEAs provide a direct route to these types of lesions, avoiding circuitous surgical corridors as well as obviating the need to work through the network of neurovascular structures along the subarachnoid space. ${ }^{26}$ 
TABLE 4. Endoscopic endonasal resection of epidermoid and dermoid cysts

\begin{tabular}{|c|c|c|c|c|}
\hline Authors \& Year & Patients & Total Resection & Complications & Follow-Up \\
\hline Weiss et al., 1998 & 2 & $2 / 2$ & None & $24 \mathrm{mos}$ \\
\hline Düz et al., 2007 & 1 & $1 / 1$ & None & $6 \mathrm{mos}$ \\
\hline Esposito et al., 2005 & 2 & $0 / 2$ & $1 \mathrm{CN}$ palsy, 1 CSF leak, 1 postop infection & 12 mos \\
\hline Schuster et al., 2011 & 2 & $2 / 2$ & None & $6-12$ mos \\
\hline McCoul et al., 2012 & 3 & $2 / 3$ & 1 CSF leak & $7-36$ mos \\
\hline Re et al., 2012 & 2 & $2 / 2$ & None & $12-48$ mos \\
\hline Mammis et al., 2013 & 1 & NR & Tension pneumocephalus & Case report \\
\hline Yoneoka et al., 2014 & 1 & $1 / 1$ & Transient visual impairment & $4 \mathrm{mos}$ \\
\hline Present study & 21 & $8 / 21$ & $\begin{array}{l}5 \text { CSF leak, } 4 \text { postop infection, } 4 \text { hydrocephalus, } 1 \\
\text { vasospasm/stroke, } 1 \text { hypopituitarism }\end{array}$ & 2-79 mos \\
\hline
\end{tabular}

$\mathrm{NR}=$ not reported.

A recent case series of EEA in the pediatric population previously reported by our group (Chivukula et al. ${ }^{6}$ ), which included the resection of 6 epidermoid/dermoid cysts, was not included in this table.

Endoscopic endonasal transfrontal approaches provide adequate exposure of the frontonasal junction and may be a valuable option for nasal dermoids with and without intracranial extension. In patients with cutaneous involvement, the endonasal approach may be used in combination with a small midline skin incision (to access the superficial tract) to achieve total resection of the lesion. 5,30

Endoscopic endonasal transplanum approaches are well suited for cysts located in the suprasellar cistern. This direct approach from below allows better control of the delicate vasculature of the optic chiasm and nerves, thus minimizing the risk of postoperative loss of vision. ${ }^{23}$ The superior hypophyseal artery, which gives rise to most of this vasculature, is better visualized endonasally than with any transcranial approach, which may also decrease the risk of visual loss as well as pituitary insufficiency. Regardless, hypopituitarism remains a risk with suprasellar tumors, as illustrated by the one occurrence in our case series.

Endoscopic endonasal transclival approaches are ideal for cysts located in the ventral aspect of the brainstem. The interpeduncular cistern may be approached endonasally with the aid of an interdural pituitary transposition..$^{10}$ In our series, this maneuver was employed in 1 case (case 17). It allowed total resection of the cyst extension into the cistern with preservation of pituitary and cranial nerve function. The prepontine cistern may be reached directly by a standard transclival approach, where the clival bone located between the bony prominences of the paraclival segments of the internal carotid arteries (ICAs) is removed. Clear visualization of the ventral surface of the pons, the basilar artery, and its branches is achieved. The use of angled endoscopes and removal of the bone overlying the paraclival ICAs can allow their mobilization and facilitate lateral dissection, though the sixth cranial nerves at the level of Dorello's canal limit this dissection. The approach may be also extended inferiorly by performing a nasopharyngectomy to the level permitted by the hard palate and drilling the underlying bone of the lower clivus/foramen magnum. This maneuver provides an unparalleled exposure of the premedullary cistern. An inferolateral extension of the transclival approach, known as a "far-medial" approach, which provides exposure of the lateral aspect of the premedullary and medial aspects of the cerebellomedullary cisterns, may be performed as needed. ${ }^{28,41}$

Cysts located off midline (coronal plane) may be safely approached and resected endonasally in selected cases. In our series, a transsellar-transcavernous approach was used to resect a cyst located in the parasellar region. Due to cyst extension within the cavernous sinus and superior orbital fissure, a medial-to-lateral surgical corridor was created by the cyst, allowing its resection. An endoscopic endonasal transpterygoid approach may be used to reach cysts located within the lateral cavernous sinus, Meckel's cave, and the infratemporal/middle cranial fossa, especially when these lesions extend to the sphenoid sinus or pterygopalatine fossa. Extensive knowledge of the surgical anatomy of the transpterygoid approaches, significant experience with EES, and advanced equipment (angled scopes, image guidance) are strongly recommended to safely perform these operations. ${ }^{14,17,39}$

Postoperative CSF leak is the most relevant complication associated with EES and appears to significantly contribute to adverse outcomes, especially in the treatment of dermoid and epidermoid cysts. This is likely increased in these cases due to the propensity of these patients to develop postoperative aseptic meningitis and even hydrocephalus. ${ }^{2,11,24,35,44}$ Aseptic meningitis could present with pseudomeningocele or hydrocephalus following open surgery but, given the lack of suturable multilayer closure, may present as a delayed CSF leak following endonasal surgery. The use of the pedicled vascularized nasoseptal flap as part of a multilayer skull base reconstruction decreases the incidence of CSF leak following EES.12,13,18,19 This was wholly evident in this series, with a $100 \%$ CSF leak rate in the 2 early intradural cases in which no flap was used. This, combined with the consequences of leak in this tumor type, should lead to the dogmatic use of vascularized reconstruction in these cases, to the point of consideration of a different approach if no vascularized option is available. Significant attention must be paid to the reconstructive phase of the procedure given the propensity for failure. 


\section{Surgical Outcomes}

The rates of total cyst resection reported in the medical literature are variable, ranging from $0 \%$ to $95 \%{ }^{4,11,35,44}$ This variability is at least partially explained by the use of different assessment criteria for total cyst resection and the lack of consensus regarding the best surgical strategy (aggressive vs conservative resection). Furthermore, it is well known that microscopic resection of epidermoid cysts may be associated with a relevant number of recurrences and the false impression of total resection due to the lack of visualization of hidden remnants, especially in larger cysts and those cysts extending ventral to the brainstem. ${ }^{1,8}$ As a matter of fact, in our series, 1 patient who was initially deemed to have undergone a complete resection presented with an asymptomatic cyst recurrence 34 months after surgery.

We defined total cyst resection based on strict criteria combining the surgeon's intraoperative impression (complete removal of cyst contents and capsule) with confirmation by postoperative MRI, including diffusion-weighted imaging sequences for evaluation of epidermoid cysts. In some cases, the postoperative MRI was negative for cyst residual, although the resection was classified as near total, with small adherent fragments of cyst capsule intentionally left behind (surgeon's impression) for the sake of preservation of neurological function. Applying these rigorous assessment criteria and favoring the philosophy of conservative resection to preserve neurological function, in addition to the enhanced endoscopic visualization of the operative field (e.g., increased capacity to identify hidden remnants), we achieved a total cyst resection rate of $38.1 \%$ in our entire cohort. Although our "total resection" rates are lower than those of the majority of the craniotomy series, especially for suprasellar cysts, these data must be carefully interpreted to address the advantages and limitations of EES for epidermoid and dermoid cyst resection. In fact, considering total and near-total cyst resection as the preferable treatment options and given that these meet the typical interpretation of complete resection, we achieved this goal in $81 \%$ of all patients in our cohort, $80 \%$ of patients with suprasellar cysts, and $71.4 \%$ of patients harboring intradural cysts. These rates are likely more consistent with what is reported in the literature as "gross-total resection," which often does not include complete cyst wall removal. Not surprisingly, extradural cysts were significantly more likely to be completely resected compared with intradural cysts $(85.7 \%$ vs $14.3 \%, p=0.003)$, given the lack of concern for neurovascular damage with cyst wall removal. This is in concordance with other reports showing more favorable resection rates for extradural cysts. ${ }^{11,33}$

In addition to intradural location, higher cyst volume was a significant factor for total resection in our series. Larger cysts are more likely to present firm adhesions to the surrounding neurovascular structures due to prolonged epithelial desquamation and are, therefore, less likely to be totally resected. In a recent study, Ren et al. ${ }^{32}$ demonstrated that larger cysts are associated with the formation of granulation tissue with abundant neovascularity and cystic adhesions to the surrounding structures. They also speculated that cyst growth may result in spontaneous intracystic hemorrhage, which may be responsible for some atypical neuroimaging findings, such as the presence of contrast enhancement on preoperative MRI. Although the presence of contrast enhancement could represent, in theory, a site of stronger cyst adhesion, we were not able to find a correlation between these findings and incomplete resection. Furthermore, larger cysts may also extend into regions that are difficult to approach endonasally, such as the CPA cistern, access to which is blocked by the $\mathrm{CN}$ VII-VIII complex. Involvement of the hypothalamus may preclude total resection of larger suprasellar cysts.

Prior surgical manipulation may enhance cyst adherence to surrounding structures by inducing a stronger inflammatory reaction, thereby decreasing the likelihood of total cyst resection. ${ }^{34}$ Others have mentioned that dermoid cysts tend to recur more aggressively and are more difficult to resect at reoperation. ${ }^{11}$ There are also reports of adverse outcomes and progressive neurological deterioration in patients who have undergone repeated surgeries for recurrent cysts. ${ }^{3}$ Despite these risks, recurrent disease was not associated with an increased number of complications or considered a limiting factor for incomplete cyst resection in our series. This may be due, in part, to the use of a "virgin" approach to the tumors, avoiding prior scar other than at the periphery of the tumor. It also likely reflects careful case selection, with other craniotomic approaches used for more laterally based tumors.

As previously presented, direct iatrogenic neurovascular injuries were rarely observed in our series. Only 1 patient developed new permanent hypopituitarism as a result of extensive pituitary stalk manipulation to achieve adequate decompression of the optic apparatus, and 2 patients had transient CN VI palsies. There were no intraoperative vascular injuries. Enhanced endoscopic visualization, direct access into the cyst, and a more controlled cyst resection provided by the endonasal route may explain these results, especially for those lesions located at the suprasellar and prepontine cisterns.

\section{Postoperative Intracranial Infection}

Aseptic meningitis (lymphocytic pleocytosis with negative gram stain/culture) is a typical complication following epidermoid and dermoid cyst resection via open transcranial approaches, estimated to occur in up to $40 \%$ of patients who undergo incomplete resection and likely related to the amount of the retained cyst, more specifically the cyst capsule. ${ }^{4,35,44}$ The perioperative administration of steroids, care to minimize spillage of cyst contents into the subarachnoid cisterns, and copious saline irrigation of the cisterns at the end of the operation to remove all loose cyst debris may serve as preventive measures to decrease the risk of this complication. . $3,11,24,34,35,40,43,44$ In our series, classic aseptic meningitis occurred in only 1 patient $(7.1 \%$ of all intradural cases). However, it is possible that the typical aseptic meningitis symptoms are clouded by CSF leak, which may occur as a result of the increased intracranial pressure associated with aseptic meningitis.

The most significant complication in this series was bacterial meningitis and/or intracranial abscess (postoperative intracranial infection), which occurred in 4 patients (19\% of all cases and $28.6 \%$ of all intradural cases). This risk is significantly higher than has been reported for patients with other types of tumors, even with similar CSF 

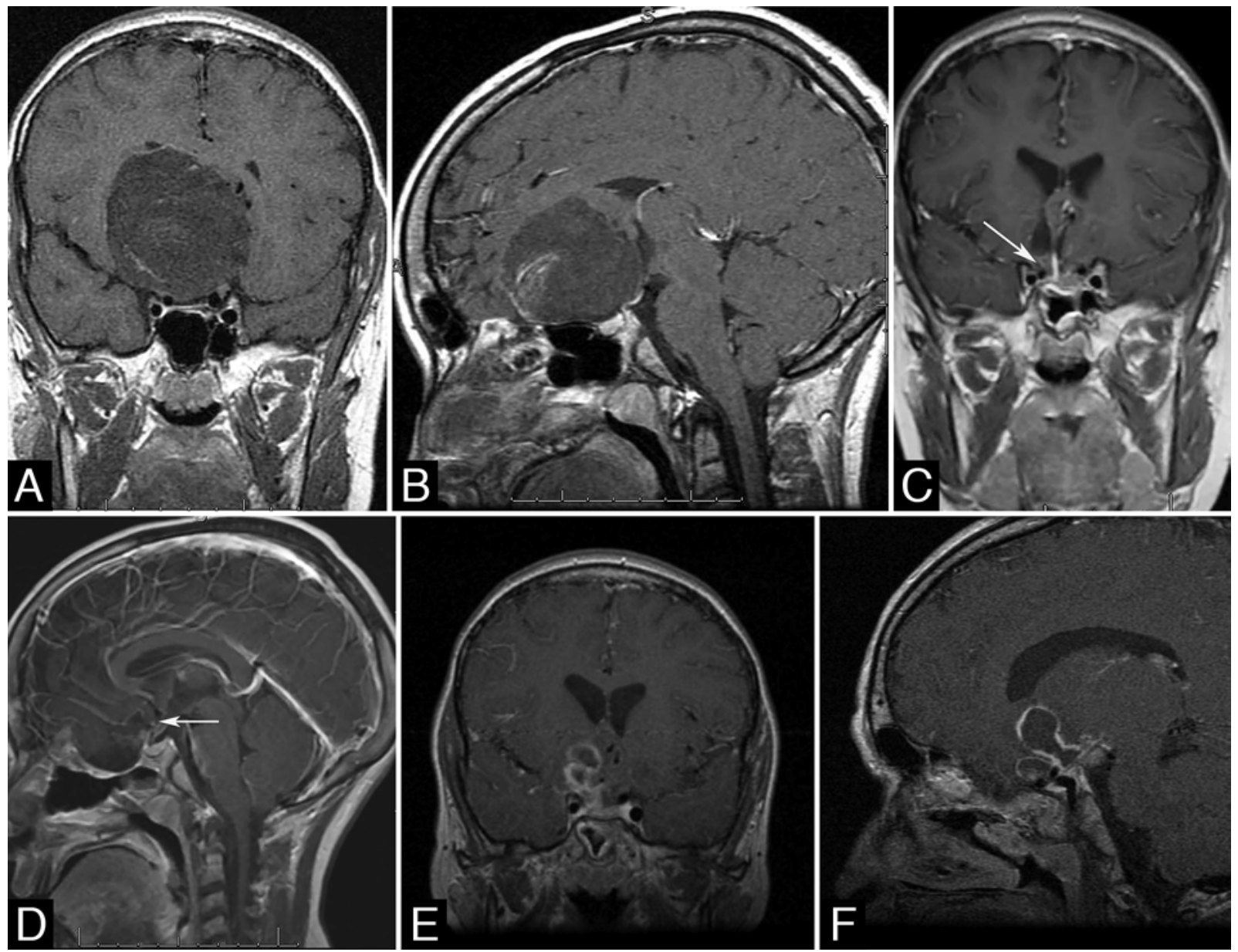

FIG. 3. Case 5. Preoperative and postoperative T1-weighted contrast-enhanced MR images obtained in an 11-year-old patient who underwent resection of a suprasellar dermoid cyst and subsequently developed an intracranial abscess. A and B: Preoperative coronal (A) and sagittal (B) images showing a large suprasellar dermoid cyst. $\mathbf{C}$ and D: Initial postoperative coronal (C) and sagittal (D) images showing a small residual (arrows, $C$ and D) attached to the right hypothalamus. $E$ and F: Follow-up coronal (E) and sagittal (F) images obtained 6 months after surgery revealing an intracranial abscess. The abscess was successfully treated with endoscopic endonasal surgical drainage and broad-spectrum antibiotic therapy.

leak rates and rates of infection that range from $3 \%$ to $8 \% .{ }^{20-23}$ Larger cysts were significantly associated with incomplete resection $(\mathrm{p}=0.002)$ and increased risk of postoperative intracranial infection $(p=0.012)$, and there was a trend toward increased risk of infection in subtotal compared with total resection $(\mathrm{p}=0.091)($ Tables 2 and 3$)$. The trend toward increased rate of infection following subtotal resection in this study may lend further support to greater degree of resection and certainly should play a role in approach selection. Moreover, and not surprisingly, postoperative CSF leak was also significantly associated with the occurrence of bacterial meningitis $(p=0.028)$. It should be also emphasized that among our 9 intradural cases without postoperative CSF leak, infection occurred in only 1 patient $(11.1 \%)$, which reinforces the findings published by Kono et al. ${ }^{20}$ suggesting that the incidence of postoperative intracranial infection following EES is comparable to that in open transcranial approaches, unless postoperative CSF leakage occurs.

More severe complications (intracranial abscess) were most frequently observed in patients who had a combina- tion of subtotal resection and postoperative CSF leak. Of note, in 2 of 3 cases of intracranial abscess, these factors were common markers for a lengthy recovery and the 1 adverse outcome. We believe that, in these situations, larger amounts of avascular cyst contents may seed, retain microorganisms, and serve as an ideal growth medium in the setting of CSF fistula. Interestingly, 1 patient (case 9) developed a brain abscess 6 months after the procedure with no history of postoperative CSF leak or warning signs of infection (Fig. 3).

Therefore, EEA is recommended for resection of epidermoid or dermoid cysts if a total or near-total resection is anticipated and a multilayer reconstruction of the cranial base, including vascularized tissue such as the pedicled nasoseptal flap, is possible. In cases where a large residual $(>1 \mathrm{~cm})$ is expected postoperatively or vascularized reconstructive options are limited, EEA may not be ideal because of the potential for catastrophic infectious complications, although anatomical relationships remain critical in selection of the approach. Additionally, in cases of very large cysts, where a staged operation may be indi- 
cated, EEA should not be used as the first procedure for cyst debulking to minimize the risk of major intracranial infection (i.e., abscess) associated with large residuals. The disadvantage of CSF leak and infection should be balanced against the main advantage of EEA, which remains its wide midline corridor for medial tumors, allowing for minimal or no neurovascular manipulation. This is directly illustrated by the lack of cranial nerve palsies or vascular injuries in the context of a high CSF leak rate.

\section{Study Limitations}

The strength of our study is limited by retrospective data collection, potential referral selection bias, and small sample size. The use of an approximation method for assessment of cyst volume is another limitation, particularly for irregularly shaped lesions. However, volumetric analysis methods were not available for most cases. Moreover, the evaluation of postoperative images may be challenging as the differentiation between gross-total and near-total resection may not be completely accurate in the skull base, although experienced skull base radiologists from our institution coordinated this evaluation. Longer follow-up is needed to provide a reliable evaluation of cyst recurrences. A randomized control trial would be necessary to provide a fair comparison between open transcranial and endoscopic endonasal approaches in terms of surgical outcomes and complications for similar cysts, but this is unlikely to occur given the rarity of these lesions and the lack of consensus regarding the best surgical strategy.

\section{Conclusions}

EES for epidermoid and dermoid cysts, although rarely reported, may be safely and effectively used in wellselected cases. The EEA provides a direct surgical route to lesions located at the ventral aspect of the cranial base with less neurovascular manipulation and fosters a more controlled dissection by promoting enhanced visualization of the cyst and surrounding neurovascular structures. This route results in low rates of cranial nerve palsies.

However, the endoscopic endonasal resection of dermoid and epidermoid cysts may be challenging, especially for larger lesions, which tend to be more adherent to surrounding structures and may extend into regions that are difficult to approach endonasally, such as the CPA cistern. Moreover, larger cyst residuals and postoperative CSF leak are associated with the occurrence of postoperative intracranial infection and potentially adverse surgical outcomes. Therefore, EES for epidermoid and dermoid cyst resection is ideally recommended for those cases where a total or near-total resection is feasible in addition to a multilayer cranial base reconstruction with vascularized tissue to minimize these risks. The surgery should be undertaken by a team with considerable endoscopic skull base experience who are comfortable with bimanual endonasal microsurgical dissection and vascularized nasal flaps.

\section{Acknowledgments}

We thank Yue-Fang Chang, PhD, Research Assistant Professor, Department of Neurosurgery, University of Pittsburgh School of Medicine, for the statistical analysis of the surgical results. We are also thankful to Dr. Amin B. Kassam, Department of Neurosurgery, Aurora Health Care, Milwaukee, Wisconsin, and to Dr. Daniel M. Prevedello, Department of Neurological Surgery, and Dr. Ricardo L. Carrau, Department of Otolaryngology-Head \& Neck Surgery, The Ohio State University Medical College, Columbus, Ohio, for their involvement in the clinical and operative management of some of the patients prior to 2010. The first author wishes to thank Stephanie L. Henry, RN, for her remarkable assistance with data collection.

\section{References}

1. Abolfotoh M, Bi WL, Hong CK, Almefty KK, Boskovitz A, Dunn IF, et al: The combined microscopic-endoscopic technique for radical resection of cerebellopontine angle tumors. J Neurosurg 123:1301-1311, 2015

2. Ahmed I, Auguste KI, Vachhrajani S, Dirks PB, Drake JM, Rutka JT: Neurosurgical management of intracranial epidermoid tumors in children. Clinical article. J Neurosurg Pediatr 4:91-96, 2009

3. Altschuler EM, Jungreis CA, Sekhar LN, Jannetta PJ, Sheptak PE: Operative treatment of intracranial epidermoid cysts and cholesterol granulomas: report of 21 cases. Neurosurgery 26:606-614, 1990

4. Berger MS, Wilson CB: Epidermoid cysts of the posterior fossa. J Neurosurg 62:214-219, 1985

5. Caldarelli M, Massimi L, Kondageski C, Di Rocco C: Intracranial midline dermoid and epidermoid cysts in children. $\mathbf{J}$ Neurosurg 100 (5 Suppl Pediatrics):473-480, 2004

6. Chivukula S, Koutourousiou M, Snyderman CH, FernandezMiranda JC, Gardner PA, Tyler-Kabara EC: Endoscopic endonasal skull base surgery in the pediatric population. $\mathbf{J}$ Neurosurg Pediatr 11:227-241, 2013

7. Düz B, Secer HI, Tosun F, Gonul E: Endoscopic endonasal resection of a midline intradural frontobasal dermoid tumour. Minim Invasive Neurosurg 50:363-366, 2007

8. Ebner FH, Roser F, Thaher F, Schittenhelm J, Tatagiba M: Balancing the shortcomings of microscope and endoscope: endoscope-assisted technique in microsurgical removal of recurrent epidermoid cysts in the posterior fossa. Minim Invasive Neurosurg 53:218-222, 2010

9. Esposito F, Becker DP, Villablanca JP, Kelly DF: Endonasal transsphenoidal transclival removal of prepontine epidermoid tumors: technical note. Neurosurgery 56 (2 Suppl):E443, 2005

10. Fernandez-Miranda JC, Gardner PA, Rastelli MM Jr, PerisCelda M, Koutourousiou M, Peace D, et al: Endoscopic endonasal transcavernous posterior clinoidectomy with interdural pituitary transposition. J Neurosurg 121:91-99, 2014

11. Gormley WB, Tomecek FJ, Qureshi N, Malik GM: Craniocerebral epidermoid and dermoid tumours: a review of 32 cases. Acta Neurochir (Wien) 128:115-121, 1994

12. Hadad G, Bassagasteguy L, Carrau RL, Mataza JC, Kassam A, Snyderman CH, et al: A novel reconstructive technique after endoscopic expanded endonasal approaches: vascular pedicle nasoseptal flap. Laryngoscope 116:1882-1886, 2006

13. Harvey RJ, Parmar P, Sacks R, Zanation AM: Endoscopic skull base reconstruction of large dural defects: a systematic review of published evidence. Laryngoscope 122:452-459, 2012

14. Kasemsiri P, Solares CA, Carrau RL, Prosser JD, Prevedello DM, Otto BA, et al: Endoscopic endonasal transpterygoid approaches: anatomical landmarks for planning the surgical corridor. Laryngoscope 123:811-815, 2013

15. Kassam A, Snyderman CH, Mintz A, Gardner P, Carrau RL: Expanded endonasal approach: the rostrocaudal axis. Part I. Crista galli to the sella turcica. Neurosurg Focus 19(1):E3, 2005

16. Kassam A, Snyderman CH, Mintz A, Gardner P, Carrau RL: Expanded endonasal approach: the rostrocaudal axis. Part II. 
Posterior clinoids to the foramen magnum. Neurosurg Focus 19(1):E4, 2005

17. Kassam AB, Gardner P, Snyderman C, Mintz A, Carrau R: Expanded endonasal approach: fully endoscopic, completely transnasal approach to the middle third of the clivus, petrous bone, middle cranial fossa, and infratemporal fossa. Neurosurg Focus 19(1):E6, 2005

18. Kassam AB, Prevedello DM, Carrau RL, Snyderman CH, Thomas A, Gardner P, et al: Endoscopic endonasal skull base surgery: analysis of complications in the authors' initial 800 patients. J Neurosurg 114:1544-1568, 2011

19. Kassam AB, Thomas A, Carrau RL, Snyderman CH, Vescan A, Prevedello D, et al: Endoscopic reconstruction of the cranial base using a pedicled nasoseptal flap. Neurosurgery 63 (1 Suppl 1):ONS44-ONS53, 2008

20. Kono Y, Prevedello DM, Snyderman CH, Gardner PA, Kassam AB, Carrau RL, et al: One thousand endoscopic skull base surgical procedures demystifying the infection potential: incidence and description of postoperative meningitis and brain abscesses. Infect Control Hosp Epidemiol 32:7783,2011

21. Koutourousiou M, Fernandez-Miranda JC, Wang EW, Snyderman $\mathrm{CH}$, Gardner PA: Endoscopic endonasal surgery for olfactory groove meningiomas: outcomes and limitations in 50 patients. Neurosurg Focus 37(4):E8, 2014

22. Koutourousiou M, Gardner PA, Tormenti MJ, Henry SL, Stefko ST, Kassam AB, et al: Endoscopic endonasal approach for resection of cranial base chordomas: outcomes and learning curve. Neurosurgery 71:614-625, 2012

23. Koutourousiou M, Fernandez-Miranda JC, Stefko ST, Wang EW, Snyderman CH, Gardner PA: Endoscopic endonasal surgery for suprasellar meningiomas: experience with 75 patients. J Neurosurg 120:1326-1339, 2014

24. Lopes M, Capelle L, Duffau H, Kujas M, Sichez JP, Van Effenterre R, et al: [Surgery of intracranial epidermoid cysts. Report of 44 patients and review of the literature.] Neurochirurgie 48:5-13, 2002 (Fr)

25. Mammis A, Agarwal N, Eloy JA, Liu JK: Intraventricular tension pneumocephalus after endoscopic skull base surgery. J Neurol Surg A Cent Eur Neurosurg 74 (Suppl 1):e96e99, 2013

26. McCoul ED, Chow S, Lee DL, Anand VK, Schwartz TH: Endoscopic endonasal approach for resection of ventral skull base keratinaceous cysts. Int Forum Allergy Rhinol 2:258263, 2012

27. Miller ME, Mastrodimos B, Cueva RA: Hearing preservation in management of epidermoids of the cerebellopontine angle: CPA epidermoids and hearing preservation. Otol Neurotol 33:1599-1603, 2012

28. Morera VA, Fernandez-Miranda JC, Prevedello DM, Madhok R, Barges-Coll J, Gardner P, et al: "Far-medial" expanded endonasal approach to the inferior third of the clivus: the transcondylar and transjugular tubercle approaches. Neurosurgery 66 (6 Suppl Operative):211-220, 2010

29. Osborn AG, Preece MT: Intracranial cysts: radiologicpathologic correlation and imaging approach. Radiology 239:650-664, 2006

30. Pinheiro-Neto CD, Snyderman CH, Fernandez-Miranda J, Gardner PA: Endoscopic endonasal surgery for nasal dermoids. Otolaryngol Clin North Am 44:981-987, ix, 2011

31. Re M, Tarchini P, Macrì G, Pasquini E: Endonasal endoscopic approach for intracranial nasal dermoid sinus cysts in children. Int J Pediatr Otorhinolaryngol 76:1217-1222, 2012

32. Ren X, Lin S, Wang Z, Luo L, Jiang Z, Sui D, et al: Clinical, radiological, and pathological features of 24 atypical intracranial epidermoid cysts. J Neurosurg 116:611-621, 2012

33. Rubin G, Scienza R, Pasqualin A, Rosta L, Da Pian R: Craniocerebral epidermoids and dermoids. A review of 44 cases. Acta Neurochir (Wien) 97:1-16, 1989
34. Samii M, Tatagiba M, Piquer J, Carvalho GA: Surgical treatment of epidermoid cysts of the cerebellopontine angle. J Neurosurg 84:14-19, 1996

35. Safavi-Abbasi S, Di Rocco F, Bambakidis N, Talley MC, Gharabaghi A, Luedemann W, et al: Has management of epidermoid tumors of the cerebellopontine angle improved? A surgical synopsis of the past and present. Skull Base 18:85-98, 2008

36. Schiefer TK, Link MJ: Epidermoids of the cerebellopontine angle: a 20-year experience. Surg Neurol 70:584-590, 2008

37. Schipper J, Ridder GJ, Arapakis I, Gellrich NC, Spetzger U, Maier W: [Neurophysiologic intraoperative monitoring to preserve cranial nerve function in base of skull surgery.] HNO 52:897-907, 2004 (Ger)

38. Schuster D, Riley KO, Cure JK, Woodworth BA: Endoscopic resection of intracranial dermoid cysts. J Laryngol Otol 125:423-427, 2011

39. Snyderman CH, Pant H, Carrau RL, Prevedello D, Gardner P, Kassam AB: What are the limits of endoscopic sinus surgery?: the expanded endonasal approach to the skull base. Keio J Med 58:152-160, 2009

40. Talacchi A, Sala F, Alessandrini F, Turazzi S, Bricolo A: Assessment and surgical management of posterior fossa epidermoid tumors: report of 28 cases. Neurosurgery 42:242-252, 1998

41. Vaz-Guimaraes Filho F, Wang EW, Snyderman CH, Gardner PA, Fernandez-Miranda JC: Endoscopic endonasal "far-medial" transclival approach: surgical anatomy and technique. Op Tech Otolaryngol 24:222-228, 2013

42. Weiss DD, Robson CD, Mulliken JB: Transnasal endoscopic excision of midline nasal dermoid from the anterior cranial base. Plast Reconstr Surg 102:2119-2123, 1998

43. Yamakawa K, Shitara N, Genka S, Manaka S, Takakura K: Clinical course and surgical prognosis of 33 cases of intracranial epidermoid tumors. Neurosurgery 24:568-573, 1989

44. Yaşargil MG, Abernathey CD, Sarioglu AC: Microneurosurgical treatment of intracranial dermoid and epidermoid tumors. Neurosurgery 24:561-567, 1989

45. Yoneoka Y, Watanabe N, Kohno M, Satoh D, Takahashi H, Fujii Y: Technical note: Endoscopic resection of a dermoid cyst anchored to the anterior optic chiasm. Interdiscip Neurosurg 1:21-25, 2014

\section{Disclosures}

Dr. Snyderman reports being a consultant for SPIWay LLC.

\section{Author Contributions}

Conception and design: Vaz-Guimaraes. Acquisition of data: Gardner, Vaz-Guimaraes, Koutourousiou, Tyler-Kabara, Fernandez-Miranda, Wang, Snyderman. Analysis and interpretation of data: Gardner, Vaz-Guimaraes, de Almeida, Fernandez-Miranda, Wang, Snyderman. Drafting the article: Vaz-Guimaraes. Critically revising the article: all authors. Reviewed submitted version of manuscript: Vaz-Guimaraes. Approved the final version of the manuscript on behalf of all authors: Gardner. Study supervision: Gardner.

\section{Supplemental Information}

\section{Previous Presentations}

Portions of this work were presented at the North American Skull Base Society 24th Annual Meeting, San Diego, California, February 2014, and the Congress of Neurological Surgeons Annual Meeting, San Francisco, California, October 2013.

\section{Correspondence}

Paul A. Gardner: UPMC Center for Cranial Base Surgery, Pittsburgh,PA.gardpa@upmc.edu. 